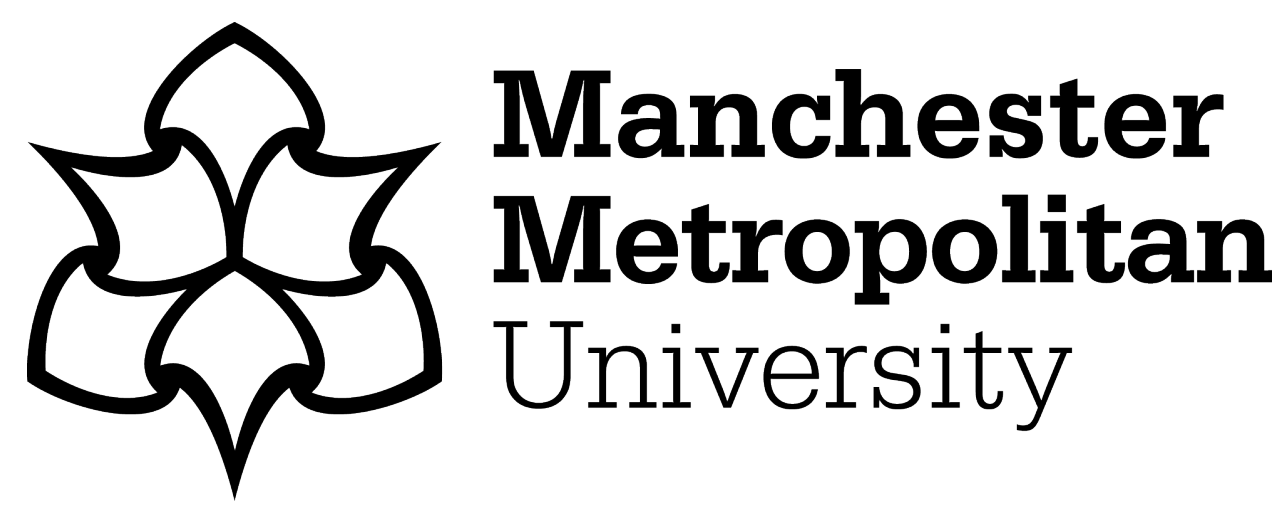

Dao, Phung ORCID logoORCID: https://orcid.org/0000-0002-8612-5589, Trofimovich, Pavel and Kennedy, Sara (2018) Structural alignment in L2 taskbased interaction. ITL: International journal of applied linguistics, 169 (2). pp. 293-320. ISSN 0019-0829

Downloaded from: https://e-space.mmu.ac.uk/623458/

Version: Accepted Version

Publisher: John Benjamins Publishing

DOI: https://doi.org/10.1075/itl.17021.dao

Please cite the published version 
Cited as: Dao, P., Trofimovich, P., \& Kennedy, S. (2018). Structural alignment in L2 task-based interaction. ITL-International Journal of Applied Linguistics, 169(2), 293-320.

\section{Structural alignment in L2 task-based interaction}

Abstract

This study investigated L2 structural alignment, the tendency for interlocutors to reuse a syntactic structure present in recent discourse, focusing on two information-gap interactive tasks. Thirty-four university students from diverse language backgrounds, recruited from different academic programs at a Canadian English-medium university, carried out the two information-gap interactive tasks in dyads. Interaction data were transcribed and coded for instances of structural alignment and the alignment's characteristics in terms of structure type and accuracy. Results indicated that structural alignment occurred in L2 task-based interaction generated by both tasks. This structural repetition was linked to an improved accuracy of subsequent language production. Furthermore, the two tasks were associated with different structures that were converged on, and with varying degrees of structural alignment. These findings are discussed in terms of effects of task features on structural alignment, and the role of structural alignment in subsequent language production.

Key words: structural alignment, language production, task features, and task-based interaction 
Cited as: Dao, P., Trofimovich, P., \& Kennedy, S. (2018). Structural alignment in L2 task-based interaction. ITL-International Journal of Applied Linguistics, 169(2), 293-320.

\section{Introduction}

One central idea in second language (L2) acquisition-particularly within interactionist perspectives (Gass, 1997; Long, 1996; Mackey, 2007, 2012; Pica, 1994)—is that there is a relationship between interaction and subsequent L2 production accuracy. The positive impact of interaction on subsequent L2 production is generally attributed to several characteristics of interaction, which include comprehensible input, pushed output, and interactional feedback, all linked to increase in production accuracy of various linguistic dimensions of learner language (Mackey, 2012; Mackey \& Gass, 2006; Swain, 1995, 2005). In light of the link between interaction and L2 production, a recent focus of L2 interaction research has shifted to investigating specific conditions in which interaction facilitates subsequent production accuracy and creates learning opportunities (Mackey, 2007; McDonough \& Kim, 2009). Situated within this research, the current study investigated one under-researched aspect of L2 interaction — structural alignment — to obtain a better understanding of the degree to which it might be involved in L2 subsequent production accuracy.

Structural alignment refers to the tendency for interlocutors to reuse a structure they have experienced in recent discourse through comprehension or production, as opposed to an alternative structure which expresses the same meaning (Bock, 1986). Structural alignment is also known as syntactic convergence or syntactic priming; however, to emphasize the nature of unscripted communication generated by communicative tasks, the term "structural alignment" is used. Structural alignment exemplifies broader alignment phenomena whereby interlocutors converge on common language patterns (lexical expressions, grammar structures, and pronunciation) produced either by themselves (within-speaker alignment) or conversation partners (between-speaker alignment) as communication unfolds (Pickering \& 
Cited as: Dao, P., Trofimovich, P., \& Kennedy, S. (2018). Structural alignment in L2 task-based interaction. ITL-International Journal of Applied Linguistics, 169(2), 293-320.

Garrod, 2004, 2013; Garrod \& Pickering, 2009). The objective of this study was to investigate the extent to which structural alignment, including within- and between-speaker alignment, is involved in task-based interaction among L2 learners, with the overall goal of clarifying its role in interaction-driven learning.

\section{Structural alignment in task-based interaction}

When speakers engage in interactive language use, they tend to adopt and repeatedly use their own or each other's language patterns, rather than alternative structures with the same meaning. For example, when comparing pictures in an information-gap task, a speaker might use a relative clause structure (I see a bird that's yellow) in place of a perfectly acceptable alternative (I see a yellow bird) after producing and/or hearing the same structure (There is a house that is blue) in a previous description by himself or his interlocutor. The precise cognitive and social functions of structural alignment are still under debate, including whether structural alignment is a means for interlocutors to decrease processing effort (e.g., Smith \& Wheeldon, 2001), whether it reflects an implicit learning mechanism (e.g., Chang, Dell, Bock, \& Griffin, 2000), and/or serves to promote mutual understanding in interaction (e.g., Pickering \& Garrod, 2004, 2013). Nonetheless, structural alignment is a pervasive phenomenon, attested in various populations of language users, including L2 speakers (Costa, Pickering, \& Sorace, 2008; Kim \& McDonough, 2008; McDonough, 2011; Authors, XXXX; Shin \& Christianson, 2012).

The pervasive nature of structural alignment as an interaction phenomenon makes it particularly interesting for L2 interaction researchers focusing on the relationship between structural alignment and L2 production/learning. One theoretical explanation of how structural alignment can bring about positive impacts on L2 production and learning centres on the activation account of alignment (Bock, 1986; Branigan, Pickering, \& Cleland, 2010; 
Cited as: Dao, P., Trofimovich, P., \& Kennedy, S. (2018). Structural alignment in L2 task-based interaction. ITL-International Journal of Applied Linguistics, 169(2), 293-320.

Branigan, Pickering, Pearson, \& McLean, 2010; Pickering \& Garrod, 2004; Pickering \& Ferreira, 2008). As speakers encounter repeated uses of specific structures (e.g., passives, datives, or relative clauses), either in comprehension or production, they activate their mental representations for these structures or rules associated with processing them. This activation appears to persist in time, enabling recently experienced structures to be more readily available for comprehension or production, compared to structures that have not occurred in recent discourse.

There is evidence from L2 interaction research that structural alignment is linked to subsequent L2 production and development. McDonough and Mackey (2008) investigated Thai L2 English learners' production of wh-questions in response to scripted 'primes' or models of target question forms in the speech of a researcher interacting with learners. They reported that learners who demonstrated structural alignment (i.e., uptake of the structures modeled by the interlocutor) were likely to produce more advanced wh-questions on the posttest following the interaction, compared to their pretest performance. In addition, when investigating the impact of structural alignment on production of wh-questions, McDonough and Kim (2009) found that the learners produced more accurate wh-questions in response to primes of this target structure when the prompts included lexical diversity. In another study, Jiang and Huang (2015) examined the effect of structural alignment on Chinese learners' production of the English double-object dative construction. The learners who received examples of the target structure produced significantly more double-object datives in both immediate and delayed posttests, relative to pretest performance, compared to those who were not primed with double-object datives.

\section{Structural alignment and task features}


Cited as: Dao, P., Trofimovich, P., \& Kennedy, S. (2018). Structural alignment in L2 task-based interaction. ITL-International Journal of Applied Linguistics, 169(2), 293-320.

To further explore the link between structural alignment and L2 subsequent production, interaction researchers have examined several features of interaction which can promote alignment, typically as part of priming (alignment) tasks. In a typical priming task, interlocutors are presented with alternating sets of materials, some of which contain samples of target structures which are delivered by one speaker (i.e., primes) while others require the other speaker to generate a structure on his or her own, using a few provided lexical items (i.e., targets). Structural alignment is established when the speaker generating a structure reuses the same structure as in his or her interlocutor's prime utterances, with greater incidence of the target structures preceded by primes compared to the occurrence of the target structures not preceded by primes (McDonough \& Mackey, 2008; Authors, XXXX; Shin \& Christianson, 2012).

One task feature shown to facilitate structural alignment is lexical boost, which refers to the overlap in lexical items between the structures modeled by one speaker and the structures produced by his or her interlocutor (Kim \& McDonough, 2008; Pickering \& Branigan, 1998; Savage, Lieven, Theakston, Tomasello, 2003). For instance, if a speaker hears a prime the boy gave the book to his sister (a prepositional dative), and then is asked to describe an image of a boy giving his friend a pen using a prompt that contains the same verb give as in the prime. She is more likely to produce the boy gave the pen to his friend (another prepositional dative) than when the prompt contains a different verb such as pass, offer, or hand. Structural alignment is enhanced when L2 speakers can reuse the same lexical items as in the structure they encountered in recent discourse, compared to when speakers generate a structure with new lexical items (McDonough, 2011). In essence, alignment is magnified when the utterances in primes and targets not only contain the same structure but also share lexical items (e.g., specific verbs or nouns). Additionally, lexical diversity in syntactic 
Cited as: Dao, P., Trofimovich, P., \& Kennedy, S. (2018). Structural alignment in L2 task-based interaction. ITL-International Journal of Applied Linguistics, 169(2), 293-320.

priming materials available for L2 speakers to use facilitates subsequent production of the target structure (McDonough, 2011; McDonough \& Kim, 2009; McDonough \& Mackey, 2008; Savage, Lieven, Theakson \& Tomasello, 2006). For instance, greater lexical diversity built into priming tasks (e.g., in terms of the number of lexical verb types and question words available to L2 speakers for generating wh-questions) promoted L2 speakers' subsequent production accuracy on posttests following priming tasks (McDonough \& Kim, 2009). Greater lexical diversity also appears to help L2 speakers generalize the target structure across various lexical items, thus discouraging speakers from associating the structure with a single frequent and prototypical lexical item, such as the verb give in English dative structures (e.g., grandma gives Lucy an apple for lunch, the teacher gave essays back to students).

The choice of target structures used in an interaction task might also influence the incidence of alignment. For example, using the same type of content across tasks with English relative clauses, adverbial clauses, and passives as target structures, Authors (XXXX) found that the likelihood of structural alignment depended on the targeted structure, such that alignment occurred more readily for relative and adverbial clauses, compared to passives. In addition, the occurrence of structural alignment might be reduced when priming tasks require less turn-by-turn interaction between speakers, for example, as in a summary task, which elicits fewer between-speaker exchanges, compared to an interview task, where interlocutors have more opportunities to engage in two-way interaction (McDonough, in review). In sum, different features of interaction tasks — as designed by researchers to elicit alignment — might either reduce or enhance the extent of structural alignment.

\section{The Current Study}


Cited as: Dao, P., Trofimovich, P., \& Kennedy, S. (2018). Structural alignment in L2 task-based interaction. ITL-International Journal of Applied Linguistics, 169(2), 293-320.

One methodological feature of most previous research focusing on L2 structural alignment is that the research tasks included built-in experimental priming manipulations, carefully constructed by researchers as part of priming tasks (Jiang \& Huang, 2015; McDonough, 2011; Shin \& Christianson, 2012; Authors, XXXX). In these studies, accurate primes of target structures (wh-questions, double-object datives, passives, question forms, or relative clauses) were intentionally added to task materials, and L2 speakers were exposed to these researcher-generated materials with the intention of seeing whether speakers would replicate these structures in their own production. However, this design feature makes it impossible to determine whether structural alignment occurs in less scripted communicative tasks without target structures which are generated (and often delivered) by researchers. If structural alignment is a feature of unscripted, spontaneous L2 use, then it is important to understand whether the structures produced by L2 speakers as part of communicative tasks (whether targetlike or not) have consequences for subsequent production of these structures.

In addition, target structures used in previous structural alignment research have mostly included developmentally complex forms (e.g., dative constructions, wh-questions, passives, adverbial clauses, relative clauses) and featured only one or two structures per task, which necessarily limits the investigation of structural alignment to only a few advanced structures. Costa et al. (2008) argued that L2 users may converge on any structures to achieve mutual understanding during interaction. This raises the question of the degree of magnitude of structural alignment in communicative tasks and of the scope of alignment, in terms of the number of structures involved, as a function of task type. Given that L2 teachers might use a variety of communicative tasks in their classrooms, it is thus necessary to expand research on structural alignment to investigating structures that occur naturally in interaction in more than one type of task. 
Cited as: Dao, P., Trofimovich, P., \& Kennedy, S. (2018). Structural alignment in L2 task-based interaction. ITL-International Journal of Applied Linguistics, 169(2), 293-320.

To date, little research has examined L2 structural alignment in unscripted communication without manipulating task materials (Collentine \& Conllentine, 2013; Michel \& Smith, 2017). In Collentine and Collentine's study, synchronous computer-mediated interactions involving L2 speakers of Spanish were analyzed for incidence of nominal clauses in the speech of interlocutors. L2 speakers appeared to produce more nominal clauses when a previous utterance contained this structure than when it did not, showing evidence of interactive alignment in unscripted L2 communication. Similarly, Michel and Smith (2017) also investigated structural alignment in computer-mediated communication, particularly focusing on lexical structures. Although informative, the studies centered on computermediated interaction and targeted few pre-determined structures, leaving it unclear whether similar interactive alignment would be observed in face-to-face L2 interaction in relation to more than a single structure and whether interactive alignment (in degree of magnitude and scope of structures involved) would depend on the type of interactive task. Similarly, it is unknown whether interactive alignment might occur in a "negative" direction, given that L2 speakers often produce nontarget structures, with the consequence that L2 speakers might appropriate and reuse nontarget forms.

To address these issues, the current study explored structural alignment in interactions generated by two unscripted information-exchange communication tasks (map task, picture story). The study's focus was on documenting the occurrence of structural alignment for a range of structures across tasks and examining the relationship between structural alignment and speakers' production accuracy. Previous research has shown that both map task and picture promoted different kinds of interaction (Kim, Horton, \& Bradlow, 2010; Van Engen, Baese-Berk, Baker, Kim \& Bradlow, 2010), suggesting that they might affect the occurrence and scope (i.e., structure types) of alignment. The current study also focused on L2 users as 
Cited as: Dao, P., Trofimovich, P., \& Kennedy, S. (2018). Structural alignment in L2 task-based interaction. ITL-International Journal of Applied Linguistics, 169(2), 293-320.

interlocutors, exploring structural alignment, including both within- and between-speaker alignment as part of conversation adaptation (Reitter \& Moore, 2014), in communication between nonnative speakers who interact in a shared L2. The choice of L2 users as interlocutors reflects the current social and political context where many L2 interactions occur between nonnative language users who might not share a common language (Clark, 1992) and where most language classrooms, including those in Canada, are becoming increasingly diverse, composed of learners from different social, educational, and linguistic backgrounds (Piccardo, 2013). The following research questions were addressed:

1. Does structural alignment occur in two unscripted communicative tasks involving L2 speakers? If so, is there a difference in structural alignment (in degree of magnitude and scope of structures involved) between tasks?

2. Is there a relationship between structural alignment and speakers' production accuracy?

\section{Method}

\section{Participants}

Participants were 34 undergraduate and graduate students ( 15 females) enrolled in a degree program at a Canadian English-medium university $\left(M_{\text {age }}=29.2\right.$ years, $\left.S D=8.6\right)$. They were studying different academic disciplines including engineering (16), social sciences (10) and business (8), and spoke different first languages, including Chinese (17), Arabic (5), Farsi (4), Bengali (3), Spanish, Russian, French, Tamil, and Bulgarian (one each). Their length of residence in Canada varied from two months to 10 years $(M=2.7$ years, $S D=3.4)$. Because of the difference in admission requirements, comparable English proficiency scores were not available. However, participants self-evaluated their English ability on a 9-point scale $(1=$ poor, $9=$ excellent $)$, rating their L2 speaking at a mean of $6.5(4-8)$ and their L2 
Cited as: Dao, P., Trofimovich, P., \& Kennedy, S. (2018). Structural alignment in L2 task-based interaction. ITL-International Journal of Applied Linguistics, 169(2), 293-320.

listening at a mean of 7.0 (4-9). Despite studying in an English speaking environment, the participants reported a mean of $41 \%$ of daily English use on a $0-100 \%$ scale, suggesting that they might have used their L1 to communicate with those who share the same L1.

Participants were randomly paired with a previously unknown partner (17 speaker pairs), such that the interlocutors did not share any other language but English.

\section{Materials and procedure}

Participants performed two paired communicative information-gap tasks: a picture story task and a map task based on Anderson et al. (1991). For the picture story task, two different sets of three pictures were created from a set of six images (shown in Appendix A). While one speaker in a pair received the first set of different three pictures in random order, the other speaker got the second set of three other pictures also in random order. The pairs were asked to describe the pictures to make sense of the story. The picture story described a man reporting that his wallet was missing while checking out at a store. He accused a customer standing behind him of stealing his wallet, and thus called the store security guard. Later at home, he found out that his wallet was in his shopping bag. For the map task, each speaker had a different version of an incomplete map based on a complete map that included a route and 10 landmarks (see Appendix A). While the first incomplete version contained 10 landmarks without a route, the second version included six landmarks and a route. The goal was for both speakers to complete their map with all details that included a route and 10 landmarks. In neither task could a speaker see his or her partner's images or map. Although the two tasks asked learners to identify and exchange unknown information in order to complete the task, they were different in other respects, such as the speakers' interactive roles, their use of linguistic resources, balance of pictorial input, and especially the degree 
Cited as: Dao, P., Trofimovich, P., \& Kennedy, S. (2018). Structural alignment in L2 task-based interaction. ITL-International Journal of Applied Linguistics, 169(2), 293-320.

and kind of interaction promoted (see detailed description of task features and implementation conditions in Appendix B).

Each pair of speakers was tested individually, and the session was videorecorded (Canon Vixia HV30), with speech captured through lapel-worn wireless microphones (Sennheiser EK-100). For warmup, both speakers performed a 3-minute introductory task (find three things in common with your partner). Speakers were then given detailed instructions about each task and performed the tasks, with 7 minutes to complete each, starting with the picture story and then proceeding to the map task. A barrier positioned between the speakers prevented them from seeing each other's materials but did not obstruct face-to-face communication.

\section{Coding}

Speakers' interaction in both tasks was transcribed and verified by trained research assistants. Because the tasks were not designed to elicit specific structures, the initial analysis explored the types of most frequent structures across all dialogues. Following Goldberg (2006), structure was defined as a pairing of form and function, with a structural frame that is not predictable from its components. Because structures need to occur with sufficient frequency to be considered as an independent construction (Goldberg, 1995, 2006), a minimum frequency threshold was set for a structure to occur at least five times within an interaction, and structures with frequency of occurrence below the threshold were excluded from the analysis. This analysis identified 11 different structures with at least five repeated utterances in the whole corpus of 34 interactions in both tasks. As shown in Table 1, which also gives examples of each structure, the set of repeated structures was partially overlapping across the two tasks, including such structures as existential there and have + complement structures. However, several structures were specific to each task, such that repetitions of that 
Cited as: Dao, P., Trofimovich, P., \& Kennedy, S. (2018). Structural alignment in L2 task-based interaction. ITL-International Journal of Applied Linguistics, 169(2), 293-320.

complements, relative clauses, and infinitive structures were common in the picture task, while incidences of go + prepositional phrase (PP) and be + complement structures were restricted to the map task.

Table 1

Instances of structures per interaction

\begin{tabular}{|c|c|c|c|c|}
\hline \multirow[b]{2}{*}{ Structure } & \multicolumn{3}{|c|}{ Frequency per dialogue } & \multirow[b]{2}{*}{ Example } \\
\hline & $M$ & $S D$ & Total & \\
\hline \multicolumn{5}{|l|}{ Picture task } \\
\hline that complement & 8.59 & 3.90 & 146 & $\begin{array}{l}\text { I have a picture that, it shows that } \\
\text { the man is in the house }\end{array}$ \\
\hline have + complement & 6.59 & 5.02 & 112 & $\begin{array}{l}\text { I have two pictures about two } \\
\text { people in in a market... }\end{array}$ \\
\hline existential there & 4.41 & 3.50 & 75 & $\begin{array}{l}\text { Because on the third picture there } \\
\text { are three guys in the } \\
\text { supermarket }\end{array}$ \\
\hline relative clause & 3.82 & 3.26 & 65 & $\begin{array}{l}\text {...uh the guy who wants to steal } \\
\text { the money }\end{array}$ \\
\hline infinitive structure & 2.18 & 2.4 & 37 & Yeah he want to steal the money \\
\hline$b e+\mathrm{PP}$ & 1.35 & 1.53 & 23 & $\begin{array}{l}\text { But uh he is inside the door } \\
\text { inside of the room or not inside } \\
\text { the room }\end{array}$ \\
\hline participle structures & 1.29 & 1.69 & 22 & $\begin{array}{l}\text { There are three people waiting in } \\
\text { line for paying }\end{array}$ \\
\hline passive voice & .82 & 1.85 & 14 & The police has been asked to... \\
\hline adverbial clause & .38 & .81 & 7 & And he goes like, I don't know \\
\hline
\end{tabular}


Cited as: Dao, P., Trofimovich, P., \& Kennedy, S. (2018). Structural alignment in L2 task-based interaction. ITL-International Journal of Applied Linguistics, 169(2), 293-320.

where my wallet is

\begin{tabular}{|c|c|c|c|c|}
\hline \multicolumn{5}{|l|}{ Map task } \\
\hline$g o+\mathrm{PP}$ & 19.29 & 13.06 & 328 & $\begin{array}{l}\text { After the the pond, it go to the } \\
\text { north east }\end{array}$ \\
\hline existential there & 11.11 & 9.03 & 189 & $\begin{array}{l}\text { And from the boat there is a } \\
\text { plane aeroplane }\end{array}$ \\
\hline$b e+$ complement & 5.11 & 4.70 & 87 & $\begin{array}{l}\text { You said you said it's on top of } \\
\text { the house, yeah? }\end{array}$ \\
\hline have + complement & 7.12 & 6.31 & 66 & $\begin{array}{l}\text { You have the uh landmark but } \\
\text { you do not have the road }\end{array}$ \\
\hline
\end{tabular}

The transcripts from both tasks were then coded by the first author for evidence of structural alignment, which was operationalized, following Pickering and Garrod (2004), as talk segment where one speaker produces an utterance containing a structure (prime) which is then reused within six subsequent turns (target), with the idea that such repetition can occur between speakers (between-speaker alignment) or within the same speaker's speech (withinspeaker alignment). The span of six adjacent turns to count possible prime-target sequences was deemed comparable to previous manipulations of time lags (e.g., 2-10 intervening sentences between occurrences of structures) used to investigate long-term effects of structural alignment in lab-based research (e.g., Bock \& Griffin, 2000). The coding was chronological, in the sense that the first instance of a structure from the beginning of interaction by each pair per task was treated as a prime and its subsequent reuse (within six consecutive turns) was coded as a target. In line with prior research (e.g., Branigan, Pickering, \& Cleland, 2000), a given prime-target sequence was counted once, such that primes were never coded as targets of a previous sequence, and targets never coded as primes of the next sequence. 
Cited as: Dao, P., Trofimovich, P., \& Kennedy, S. (2018). Structural alignment in L2 task-based interaction. ITL-International Journal of Applied Linguistics, 169(2), 293-320.

To illustrate the coding of primes and targets, Excerpt 1 shows a prime $\rightarrow$ target sequence in which Speaker B reused the relative clause structure that was produced by Speaker A in the previous utterance. Excerpt 2, taken from another pair, illustrates a no prime $\rightarrow$ target sequence, with Speaking B producing a target of the relative clause without being primed by Speaker A in the preceding six turns.

\section{Excerpt 1}

1 A: ...uh the guy who wants to steal the money (prime, +accuracy, betweenspeaker)

2 B: Ok I think the first one is the man who... wear... wear glasses (target, accuracy, between-speaker)

\section{Excerpt 2}

$1 \quad \ldots \quad$ [6 preceding turns with no incidence of target structure]

2 A: He's a gentle man he has a a...

3 B: Ya ok we can assume he's the guy who lost his wallet the third one (target, +accuracy, unprimed)

4 A: Ya ya that's right the third one ya this guy the gentleman

All instances of structural alignment were also coded for three additional features: (a) the type of structure involved, (b) grammar accuracy of primes and targets, and (c) alignment between and within speakers. Excerpt 3 from the map task illustrates these additional coding categories for the existential there structure, with a fronted PP. In lines 1-4, Speaker B reuses the same structure produced earlier by Speaker A, illustrating between-speaker alignment; 
Cited as: Dao, P., Trofimovich, P., \& Kennedy, S. (2018). Structural alignment in L2 task-based interaction. ITL-International Journal of Applied Linguistics, 169(2), 293-320.

although Speaker A's prime is grammatically inaccurate due to the missing article, Speaker B's target is correct. In lines 8-12, Speaker B produces another instance of the same structure (prime), then reuses it later (target), exemplifying within-speaker alignment, with both structures produced as accurate.

Excerpt 3: Existential there structure

1 A: Ok, below the plane there is castle (prime 1,-accuracy, between-speaker)

2 B: Where is the wall, right

$3 \quad \mathrm{~A}: \mathrm{Ok}$

4 B: And a... on the left of the castle which is in the middle of the picture, almost middle there is a car (target 1, +accuracy, between-speaker)

5 A: Yeah, I have it

6 B: Oh, you have the car

$7 \quad$ A: Uhu

8 B: Beside the car on the left of the car there is a (prime 2, +accuracy, withinspeaker)

$9 \quad$ A: Lake with a fish?

10 B: Yes

11 A: I have it too.

12 B: Ok. Mmm... ok, below the - below the lake and on the r-below little above below little right too there is a forest with trees. (target $2,+$ accuracy, between-speaker) 
Cited as: Dao, P., Trofimovich, P., \& Kennedy, S. (2018). Structural alignment in L2 task-based interaction. ITL-International Journal of Applied Linguistics, 169(2), 293-320.

\section{Analysis}

After primes and targets were coded, two proportion scores per interlocutor pair were calculated, following similar research (e.g., Collentine \& Collentine, 2013; Gries, 2005). The first score was the prime $\rightarrow$ target score, computed by dividing the number of sequences where a prime was followed by a target over the total number of repeated utterances produced in each dialogue (across all structures combined), separately in each task. Similarly, the second score was the no prime $\rightarrow$ target score, calculated by dividing the number of sequences where the target structure was not preceded by a prime over the total number of repeated utterances produced in each dialogue (across all structures combined), again separately in each task. Structural alignment would be shown by higher prime $\rightarrow$ target scores, with speakers producing a structure after their interlocutors (or speakers themselves) generate the same structure. Absence of alignment would be shown by higher no prime $\rightarrow$ target scores, with speakers producing a structure even though this structure is not provided by their interlocutors (or speakers themselves) in a preceding turn.

As discussed above, separate prime $\rightarrow$ target and no prime $\rightarrow$ target scores were calculated per task so that the incidence of structural alignment could be compared across the two tasks. To enable fine-grained analyses, separate scores were also computed to investigate structural alignment as a function of such features as the type of structure involved and between- versus within-speaker alignment. Finally, to determine the relationship between structural alignment and speakers' production accuracy, the prime $\rightarrow$ target scores for each interaction per task were broken down according to the grammaticality status of primes and targets (correct prime $\rightarrow$ correct target, correct prime $\rightarrow$ incorrect target, incorrect prime $\rightarrow$ correct target, incorrect prime $\rightarrow$ incorrect target). A second coder coded $25 \%$ of the 
Cited as: Dao, P., Trofimovich, P., \& Kennedy, S. (2018). Structural alignment in L2 task-based interaction. ITL-International Journal of Applied Linguistics, 169(2), 293-320.

data independently for structural alignment and accuracy of primes and targets. Pearson $r$ was .82 for instances and Cohen's $\kappa$ was .94 for accuracy of primes and targets, which showed an acceptable level of coding consistency. In all analyses, assumptions for parametric analyses (distribution normality) were checked by using Kolmogorov-Smirnov tests.

\section{Results}

\section{Structural alignment across tasks}

The first research question asked whether structural alignment occurs in unscripted communicative tasks and whether its extent would depend on task type (see Table 2 for descriptive statistics). In both tasks, there were more instances of prime $\rightarrow$ target sequences than sequences where targets were not preceded by primes. Paired-samples $t$ tests (Bonferroni corrected) showed that the differences reached significance in the picture task, $t(16)=8.53, p$ $<.001, d=4.46$, and in the map task, $t(16)=5.79, p<.001, d=2.61$, suggesting that structural alignment occurred in both tasks. The extent of structural alignment was comparable between the tasks, as prime $\rightarrow$ target and no prime $\rightarrow$ target scores did not differ across tasks, $t(16)<.95, p>.36$.

Table 2

Occurrence of structural alignment per interaction across tasks

\begin{tabular}{lccccc}
\hline & \multicolumn{2}{c}{ Picture task } & & \multicolumn{2}{c}{ Map task } \\
\cline { 2 - 3 } \cline { 5 - 6 } Score & Sum & Proportion & & Sum & Proportion \\
\hline Primed & $17.35(8.23)$ & $.69(.09)$ & & $13.24(5.60)$ & $.65(.12)$ \\
Unprimed & $7.76(4.45)$ & $.31(.08)$ & & $7.35(4.27)$ & $.35(.11)$ \\
\hline
\end{tabular}

Note. Standard deviations appear in parentheses. 
Cited as: Dao, P., Trofimovich, P., \& Kennedy, S. (2018). Structural alignment in L2 task-based interaction. ITL-International Journal of Applied Linguistics, 169(2), 293-320.

Although structural alignment was observed in both tasks, the structures that elicited alignment varied across them (see Table 3 summarizing structures involved in alignment). In the picture task, speakers were more likely to reuse that complement (Excerpt 4) whereas go

+ PP (Excerpt 5) was the most frequent structure involved in alignment in the map task.

\section{Excerpt 4: That complement structure}

1 A: One of them there is a store - two of them show that the man in a green shirt (prime 1,-accuracy, between-speaker)

2 B: I have a picture that, it shows that the man is in the house (target 1, +accuracy, between-speaker) and its want - and he wants to open the door and go outside the house

Excerpt 5: Go + PP structure

1 B: Yes and also the road goes to the flag? (prime 2, +accuracy, betweenspeaker)

2 A: Up to flag up to flag and it will go down... (target 2, +accuracy, betweenspeaker)

3 B: Up to flag ya, it go down to the bottom of the boat (prime 3,-accuracy, between-speaker)

4 A: Bottom of the boat and it will go in between the the fish and the car (target 3, +accuracy, between-speaker)

In addition, there were a greater number of structures involved in alignment in the picture task, compared to the map task. Table 3 presents raw numbers $(k)$ of total instances of alignment and non-alignment, with each instance of alignment consisting a prime utterance 
Cited as: Dao, P., Trofimovich, P., \& Kennedy, S. (2018). Structural alignment in L2 task-based interaction. ITL-International Journal of Applied Linguistics, 169(2), 293-320.

and a target utterance, and an instance of non-alignment containing a target utterance. The structures that elicited alignment in the picture task included relative and adverbial clauses, infinitive constructions, passive voice, participle structures, existential there, be $+\mathrm{PP}$, and have + complement. Meanwhile, structures eliciting alignment in the map task comprised be $+\mathrm{PP}$, have + complement, existential there, and go + PP. In addition, structures eliciting alignment appeared to be more complex in the picture task (e.g., relative and adverbial clauses, passive voice) than those involved in alignment in the map task (e.g., be and have followed by complements). 
Cited as: Dao, P., Trofimovich, P., \& Kennedy, S. (2018). Structural alignment in L2 task-based interaction. ITL-International Journal of Applied Linguistics, 169(2), 293-320.

Table 3

Summary of structures involved in structural alignment across tasks

\begin{tabular}{|c|c|c|c|c|c|c|c|c|}
\hline \multirow[b]{3}{*}{ Structure } & \multicolumn{4}{|c|}{ Picture task } & \multicolumn{4}{|c|}{ Map task } \\
\hline & \multicolumn{2}{|c|}{ Primed } & \multicolumn{2}{|c|}{ Unprimed } & \multicolumn{2}{|c|}{ Primed } & \multicolumn{2}{|c|}{ Unprimed } \\
\hline & $k$ & $\%$ & $k$ & $\%$ & $k$ & $\%$ & $k$ & $\%$ \\
\hline existential there & 27 & 56.2 & 21 & 43.8 & 74 & 64.4 & 41 & 35.6 \\
\hline have + complement & 46 & 69.7 & 20 & 30.3 & 22 & 50.0 & 22 & 50.0 \\
\hline that complement & 62 & 73.8 & 22 & 16.2 & & & & \\
\hline relative clause & 23 & 54.8 & 19 & 45.2 & & & & \\
\hline infinitive structures & 12 & 40.0 & 13 & 52.0 & & & & \\
\hline$b e+\mathrm{PP}$ & 10 & 76.9 & 3 & 23.1 & & & & \\
\hline participle structure & 8 & 57.0 & 6 & 43.0 & & & & \\
\hline passive voice & 6 & 75.0 & 2 & 25.0 & & & & \\
\hline adverbial clause & 3 & 75.0 & 1 & 25.0 & & & & \\
\hline$g o+\mathrm{PP}$ & & & & & 139 & 73.5 & 50 & 26.5 \\
\hline$b e+$ complement & & & & & 33 & 61.1 & 21 & 38.9 \\
\hline
\end{tabular}

In terms of between- versus within-speaker alignment (summarized in Table 4), both tasks revealed similar patterns. Over $60 \%$ of all instances of structural alignment in both tasks involved within-speaker alignment. Thus, although interlocutors reused each other's structures, they were more likely to repeat the structures generated by themselves. In fact, the structural alignment in both tasks was restricted to within-speaker alignment, as the (Bonferroni adjusted) difference between prime $\rightarrow$ target and no prime $\rightarrow$ target scores was significant for within-speaker alignment scores in the picture task, $t(16)=8.40, p<.001, d=$ 
Cited as: Dao, P., Trofimovich, P., \& Kennedy, S. (2018). Structural alignment in L2 task-based interaction. ITL-International Journal of Applied Linguistics, 169(2), 293-320.

2.89 , and in the map task, $t(16)=5.82, p<.001, d=2.40$, but not for between-speaker scores in the picture task, $t(16)=1.36, p=.19$, or in the map task, $t(16)=.65, p=.53$.

Table 4

Occurrence of between- and within-speaker alignment across tasks

\begin{tabular}{|c|c|c|c|c|c|c|c|}
\hline \multicolumn{4}{|c|}{ Picture task } & \multicolumn{4}{|c|}{ Map task } \\
\hline \multicolumn{2}{|c|}{ Within } & \multicolumn{2}{|c|}{ Between } & \multicolumn{2}{|c|}{ Within } & \multicolumn{2}{|c|}{ Between } \\
\hline Sum & Proportion & Sum & Proportion & Sum & Proportion & Sum & Proportion \\
\hline 10.65 & $.64(.13)$ & 6.47 & $.36(.14)$ & 9.00 & $.63(.13)$ & 4.23 & $.37(.13)$ \\
\hline$(5.41)$ & & $(3.92)$ & & $(4.44)$ & & $(2.41)$ & \\
\hline
\end{tabular}

Note. Standard deviations appear in parentheses.

\section{Structural alignment and production accuracy}

To answer the second research question, which asked whether structural alignment is associated with speakers' production accuracy, the prime $\rightarrow$ target scores for each interaction per task were broken down according to the grammaticality status of primes and targets for comparison (correct prime $\rightarrow$ correct target, correct prime $\rightarrow$ incorrect target, incorrect prime $\rightarrow$ correct target, incorrect prime $\rightarrow$ incorrect target). As shown in Table 5, speakers provided both grammatically accurate and inaccurate primes, and reused both accurate and inaccurate structures in both tasks.

Table 5 
Cited as: Dao, P., Trofimovich, P., \& Kennedy, S. (2018). Structural alignment in L2 task-based interaction. ITL-International Journal of Applied Linguistics, 169(2), 293-320.

Occurrence of alignment (proportion) by grammaticality of primes and targets across tasks

\begin{tabular}{|c|c|c|c|c|c|c|}
\hline \multirow[b]{3}{*}{ Target } & \multicolumn{3}{|c|}{ Picture task } & \multicolumn{3}{|c|}{ Map task } \\
\hline & \multicolumn{2}{|c|}{ Prime } & \multirow[t]{2}{*}{ Unprimed } & \multicolumn{2}{|c|}{ Prime } & \multirow[t]{2}{*}{ Unprimed } \\
\hline & Accurate & Inaccurate & & Accurate & Inaccurate & \\
\hline Accurate & $.31(.20)$ & $.13(.12)$ & $.59(.28)$ & $.32(.13)$ & $.22(.11)$ & $.54(.27)$ \\
\hline Inaccurate & $.21(.11)$ & $.34(.17)$ & $.41(.27)$ & $.18(.05)$ & $.28(.15)$ & $.45(.28)$ \\
\hline
\end{tabular}

Note. Standard deviations appear in parentheses.

Paired-samples $t$ tests (Bonferroni corrected) showed that after accurate primes, there was a greater number of grammatically accurate targets than inaccurate targets in the map task, $t(16)=4.42, p=.001, d=1.41$, but not in the picture task, $t(16)=1.72, p=.104$. Similar tests also showed that after inaccurate primes, there was a greater number of grammatically inaccurate targets than accurate targets in the picture task, $t(16)=-4.34, p=$ $.001, d=1.43$, but not in the map task, $t(16)=-1.09, p=.29$. These differences were not due to incidence of correct and incorrect structures in unprimed contexts, as there was no significant difference between accurate and inaccurate structures when they were not preceded by primes in either the map task, $t(16)=.71, p=.49$, or the picture task, $t(16)=$ $1.33, p=.20$. As demonstrated in Tables 6 and 7, which break down occurrence of structural alignment for between- versus within-speaker production, these differences were also not due to different contributions of between- and within-speaker alignment. In fact, accuracy patterns in between- and within-speaker alignment were comparable within each task. In sum, speakers showed alignment towards grammatically accurate structures, but only in the map task, although the pattern was similar (but failed to reach significance) in the picture task. Speakers also showed alignment towards grammatically inaccurate structures, but only 
Cited as: Dao, P., Trofimovich, P., \& Kennedy, S. (2018). Structural alignment in L2 task-based interaction. ITL-International Journal of Applied Linguistics, 169(2), 293-320.

in the picture task, though the scores followed the same trend (but failed to reach significance) in the map task.

Table 6

Production accuracy (proportion) by type of alignment in the picture task

\begin{tabular}{lcccc}
\hline & \multicolumn{4}{c}{ Prime-target relationship } \\
\cline { 2 - 5 } Alignment & $\begin{array}{c}\text { Accurate- } \\
\text { accurate }\end{array}$ & $\begin{array}{l}\text { Accurate- } \\
\text { inaccurate }\end{array}$ & $\begin{array}{c}\text { Inaccurate- } \\
\text { accurate }\end{array}$ & $\begin{array}{r}\text { Inaccurate- } \\
\text { Inaccurate }\end{array}$ \\
\hline Within & $.33(.21)$ & $.21(10)$ & $.13(.12)$ & $.36(.18)$ \\
Between & $.29(.22)$ & $.19(.15)$ & $.14(.14)$ & $.32(.17)$ \\
\hline
\end{tabular}

Note. Standard deviations appear in parentheses.

Occurrence of alignment (proportion) by grammaticality of primes and targets across tasks

Table 7

Production accuracy (proportion) by type of alignment in the map task

\begin{tabular}{lcccc}
\hline & \multicolumn{4}{c}{ Prime-target relationship } \\
\cline { 2 - 5 } Alignment & $\begin{array}{c}\text { Accurate- } \\
\text { accurate }\end{array}$ & $\begin{array}{l}\text { Accurate- } \\
\text { inaccurate }\end{array}$ & $\begin{array}{c}\text { Inaccurate- } \\
\text { accurate }\end{array}$ & $\begin{array}{r}\text { Inaccurate- } \\
\text { Inaccurate }\end{array}$ \\
\hline Within & $.35(.18)$ & $.19(.05)$ & $.21(.12)$ & $.25(.17)$ \\
Between & $.36(.20)$ & $.16(.09)$ & $.21(.14)$ & $.26(.20)$ \\
\hline
\end{tabular}

Note. Standard deviations appear in parentheses.

\section{Discussion}

The goal of this study was to investigate the occurrence of structural alignment in unscripted interaction involving L2 users and to examine whether alignment (in degree of 
Cited as: Dao, P., Trofimovich, P., \& Kennedy, S. (2018). Structural alignment in L2 task-based interaction. ITL-International Journal of Applied Linguistics, 169(2), 293-320.

magnitude and scope of structures involved) differs between two communicative tasks and whether it is associated with speakers' production accuracy. Results showed that speakers in both picture and map tasks reused structures at comparable levels, although the magnitude of within-speaker alignment (where speakers reuse the utterances they generate themselves) was twice the size of between-speaker alignment (where speakers reuse each other's utterances). In fact, the interactive alignment in this study was largely driven by speakers reusing utterances they generated themselves in immediately preceding discourse (i.e., within the previous six speaking turns). This provides support for previous research demonstrating structural alignment in unscripted communication involving L2 users (Collectine \& Collentine, 2013) and in scripted interaction between L2 learners (McDonough, 2006; McDonough \& Mackey, 2008).

Pickering and Garrod (2004) proposed that interlocutors need to establish "common ground," or shared understanding, in order to achieve communicative goals, and one possible way of doing so would for them to coordinate (repeat and reuse) their own and/or each other's linguistic structures in dialogue. In the picture and map tasks, speakers needed to achieve common task goals (e.g., complete story or map), and thus may have increased their tendency to reuse the same structures, which resulted in the high overall rates of structural alignment (65-69\% of all repeated utterances) in both tasks. This result is in line with evidence shown by McDonough (in review), where communicative tasks involving less turnby-turn interaction between interlocutors (which presumably are less demanding in terms of speakers' need to interact to achieve a shared goal) are less likely to elicit structural alignment, compared to highly interactive tasks engaging both interlocutors (see also Collentine \& Collentine, 2013; Reitter \& Moore, 2014).

\section{Task differences in structural alignment}


Cited as: Dao, P., Trofimovich, P., \& Kennedy, S. (2018). Structural alignment in L2 task-based interaction. ITL-International Journal of Applied Linguistics, 169(2), 293-320.

Despite comparable levels of structural alignment shown for both tasks, alignment did vary as a function of task. One task effect related to differences in the most frequently repeated structures, such as that complement in the picture task and go + PP in the map task. The type of structures eliciting the most alignment was likely related to the goal of the task. For instance, the goal of the picture task was to describe two sets of pictures in order to create a coherent story. As shown in Excerpt 4, interlocutors relied on that complement structures to distinguish story participants and locations where actions took place. The goal of the map task was to identify missing landmarks and draw a route, which required interlocutors to use expressions that featured movement verbs (such as go) and to indicate both direction and location to situate the map in a landmark space, as was illustrated in Excerpt 5. One may argue that the participants converged on the same structures in each task because these structures were built into task materials purposefully (e.g., Kim \& McDonough, 2009). However, no structures were purposefully integrated into the task materials for either task. The interlocutors could choose another structure (instead of that complement) to describe the pictures or use other expressions (instead of $g o+\mathrm{PP}$ ) to give directions. Thus, it appeared that it was the interlocutors' choice of structures, and they converged on these structures as a function of alignment during interaction, which then likely facilitated their subsequent production accuracy.

Another effect of task was related to the number of structures eliciting structural alignment as well as the complexity of structures involved. Compared to the map task, the picture task featured more structures eliciting alignment. One reason for this difference is the nature and extent of communication that each task promoted. For example, the picture task promoted relatively equal division of communicative "labor" between interlocutors (Kim, Horton, \& Bradlow, 2010; Van Engen et al., 2010), providing interlocutors with more 
Cited as: Dao, P., Trofimovich, P., \& Kennedy, S. (2018). Structural alignment in L2 task-based interaction. ITL-International Journal of Applied Linguistics, 169(2), 293-320.

freedom to construct the story despite it being restricted to the available pictures. Thus, interlocutors could adopt a variety of structures, including complex ones, to describe pictures. Meanwhile, the map task typically elicited structures related to movement and its location and direction, with the consequence that only a few structures, including prepositional phrases, were predominantly used to exchange information. In sum, different tasks tend to elicit different structures and lead to different kinds of interaction, lending further support to prior research showing that task types and task characteristics impact features of interaction, such as negotiation for meaning (Lambert, Philp, \& Nakamura, 2017; Nuevo, Adams, \& Ross-Feldman, 2011; Oliver, 2002; Phung, 2017), language-related episodes (Authors, 2017; Colina \& Garcia Mayo, 2007; Kim, 2013), and language performance, in terms of complexity, accuracy, and fluency (Foster \& Skehan, 1996; Levkina \& Gilabert, 2012). The novel contribution of this study is that task type also influences the extent of structural alignment in task-based interaction, in terms of the scope of the structures eliciting alignment.

Yet another aspect of structural alignment that appeared to be influenced by task concerned the extent of between- versus within-speaker alignment. That is, speakers were more likely to reuse their own structures than to repeat the structures generated by their interlocutors, although this apparently had no influence on the incidence with which target versus nontarget structures occurred (see Tables 6 and 7). In the map task, where one interlocutor had to draw a route whereas the other had to find missing landmarks, one of the interlocutors normally adopted a more active interactive role when describing his or her version of the map, as the provider of information, while his or her partner in response adopted a less dominant role (confirming understanding), as the receiver of information (see Anderson et al., 1991). Previous research suggested that this division of communicative labor-involving more versus less dominant interactive roles_-prompts more interaction 
Cited as: Dao, P., Trofimovich, P., \& Kennedy, S. (2018). Structural alignment in L2 task-based interaction. ITL-International Journal of Applied Linguistics, 169(2), 293-320.

(Authors, 2017; Yule \& MacDonald, 1990). As shown in Excerpt 6, Speaker A, who interacts in a more dominant role, keeps using go + PP structures when describing the map, and Speaker B repeats this structure to confirm that the information is received and understood. Thus, during the entire excerpt, Speaker A repeated the structure generated by himself, while Speaker B only reused this structure when he wished to confirm the message. In essence, phases of interaction in the map task seemed to be more conducive to within- than betweenspeaker alignment.

\section{Excerpt 6}

1 A: House, ok. And then you go to the - do you have the flag Canadian flag?

2 B: Yeah.

3 A: Ok, you go to the flag. It is the next stop.

4 B: So, from the house, go to the Canadian flag?

5 A: Yeah. And then you go down. To the - there is a car. And then pond.

6 B: So there - so the line goes through the stop?

7 A: The line goes down between the pond? Like the lake there is fish there.

8 B: Yeah.

9 A: Do you have that?

10 B: Yeah.

11 A: Ok, the line, go between the pond and the car

12 B: The car?

13 A: The car.

14 B: So the line goes directly to the flag 
Cited as: Dao, P., Trofimovich, P., \& Kennedy, S. (2018). Structural alignment in L2 task-based interaction. ITL-International Journal of Applied Linguistics, 169(2), 293-320.

15 A: Yeah.

16 B: And then goes down between the lake in which there are fish in this. So the line goes between the lake and the car.

In the picture task, speakers took turns describing their set of pictures and appeared to "stick to" a set of reused structures, which resulted in more within-speaker alignment. To illustrate, in Excerpt 7, Speaker B consistently uses have + NP structures, reinforcing the use of this construction in her speech. It appears, then, that structural alignment in task-based interaction provides interlocutors with opportunities for repeated practice of specific structures, which might impact their overall L2 speaking ability and help consolidate their knowledge of these structures (McDonough \& Mackey, 2008; McDonough \& Chaikimongkol, 2010; McDonough et al., 2015).

\section{Excerpt 7}

1 B: Oh. ok ok.

2 A: Number one.

3 B: Uh this guy has a bag

4 A: Yeah.

5 B: He has a bag, and then he ...

6 A: It's a kind of yellow or orange bag.

7 B: And then he has a lamp in the door?

8 A: Yeah.

$9 \quad$ B: Or in the bed?

10 A: No, on the door. It's not important I think. 
Cited as: Dao, P., Trofimovich, P., \& Kennedy, S. (2018). Structural alignment in L2 task-based interaction. ITL-International Journal of Applied Linguistics, 169(2), 293-320.

11 B: Where's the door? Is it in the office?

12 A: Its looks like an office, but I think it's ...

13 B: He has a lamp

14 A: Not in the office. It's out of the office waiting. And he wore, he wear a green shirt, and uh pink uh.

\section{Relationship between structural alignment and production accuracy}

One important finding of this study was that structural alignment was associated with speakers' production accuracy. Evidence for speakers' increased tendency to reuse accurate L2 structures in dialogue was found in the map task, where speakers (exposed to grammatically accurate structures) tended to reuse them in grammatically accurate utterances. And a similar trend was observed in the picture task, although the effect failed to reach significance. The non-significant results in the picture task might be due to the fact that a majority of structures were quite complex (e.g., that complement, relative clause, passive voice, adverbial clauses), suggesting that these forms were more prone to errors as opposed to less complex ones which were used in the map task. The results for production accuracy of unprimed (nonaligned) structures in both tasks also speak to the importance of structural alignment in eliciting accurate language production. Put differently, when no primes of structures were present and speakers produced structures, there was no difference in production accuracy, such that grammatically accurate and inaccurate forms were produced at similar rates.

The current study also yielded evidence of speakers' appropriating and reusing their own and their interlocutors' grammatically incorrect structures. For instance, in the picture task, speakers produced more inaccurate targets following inaccurate primes, demonstrating 
Cited as: Dao, P., Trofimovich, P., \& Kennedy, S. (2018). Structural alignment in L2 task-based interaction. ITL-International Journal of Applied Linguistics, 169(2), 293-320.

negative alignment or reinforcement of grammatically incorrect utterances in speakers' own speech and in the speech of their interlocutors. This means that, throughout interaction, there were cases where interlocutors reused inaccurate structures and where they recycled accurate structures. Thus, to facilitate more accurate language production through structural alignment, linguistic structures provided in interaction need to be targetlike. Because communication analyzed in this study was elicited through communicative tasks and thus contained instances of target and nontarget language, accurate models of language need to be previewed before engaging in the task and also included in task materials, as suggested in prior research, where primes were purposely added to elicit accurate language production (McDonough, 2006; McDonough et al., 2015; Shin \& Christiansen 2012). The inclusion of accurate language models (primes), especially those targeting developmentally challenging structures, seems important because structural alignment involving these structures has the potential to provide the most benefit to L2 speakers, who often require repeated experience with such not-yet-fully-controlled constructions to promote production fluency and automaticity.

However, it was not always the case that inaccurate structures promoted the use of inaccurate structures. For example, in the map task, speakers produced relatively similar proportion of accurate and inaccurate targets after inaccurate models. One possible reason for this finding can be related to large proficiency differences among participants. That is, for between-speaker alignment, when pairs of interlocutors were of unbalanced proficiency levels (although all speakers were university-level students), inaccurate structures spoken by a lower proficiency interlocutor could be reused correctly in the speech of a higher proficiency partner. For within-speaker alignment, with high proficiency level (i.e., graduate and undergraduate students), learners were able to self-correct their previous utterance of a 
Cited as: Dao, P., Trofimovich, P., \& Kennedy, S. (2018). Structural alignment in L2 task-based interaction. ITL-International Journal of Applied Linguistics, 169(2), 293-320.

structure (i.e., primes) when producing a new subsequent utterance of that structure (i.e., target). While the current dataset did not allow for a finer grained analysis of structural alignment as a function of interlocutor proficiency (since no independent measures of speaking proficiency, besides self-reports, were available and the dataset was generally small), this issue needs to be revisited in future research. Nevertheless, in the absence of further evidence, it is plausible that paring interlocutors of different proficiency levels would be beneficial to language production from the perspective of structural alignment (Kim \& McDonough, 2008; Ohta, 2001; Storch, 2001; Watanabe \& Swain, 2007), such that a higher proficiency speaker can provide instances of target L2 structures for a lower proficiency interactant as part of unscripted communicative tasks.

\section{Limitations}

Inevitably, the study has some limitations. First, the participants were of a heterogeneous group of different proficiency levels. Therefore, future research needs to take proficiency factor into consideration with regard to its possible influence on the occurrence of structural alignment and subsequent production accuracy. Second, converged structures in the dataset were spontaneous, thus showing different degrees of linguistic complexity. It will be helpful and informative for future research to investigate whether linguistic complexity of structures has any impact on the degree of interlocutors' structural alignment and subsequent production accuracy. Third, only two convergent communicative tasks that have been shown to elicit different kinds of interactions were used in the current study. Given that language teachers may use a wide range of tasks in their teaching practice, future research may need to employ different task types (e.g., divergent vs. convergent tasks) to shed more light on the effects of task features on structural alignment in unscripted interaction.

\section{Conclusion}


Cited as: Dao, P., Trofimovich, P., \& Kennedy, S. (2018). Structural alignment in L2 task-based interaction. ITL-International Journal of Applied Linguistics, 169(2), 293-320.

The goal of this study was to investigate possible occurrence of L2 structural alignment in unscripted task-based interaction and to investigate the relationship between alignment and production accuracy. The current findings suggest that information-exchange tasks elicit structural alignment in the absence of researcher-generated materials or researcher-delivered primes, as part of communication involving L2 users. Structural alignment also appeared to be associated with accurate production of L2 structures, provided that previous instances of structures, experienced in dialogue, also involved grammatically accurate structures. This result highlights an important role of structural alignment in helping L2 speakers benefit from additional practice opportunities using and developing mastery of L2 structures, particularly those structures which are developmentally advanced. In addition, because structural alignment (in terms of the scope of the structures involved) depended on the type of task, the task variable must be considered when investigating structural alignment or creating alignment activities for use in language classrooms. While not directly investigated here, interlocutors' speaking proficiency emerged as an important factor that can influence the extent and scope of interactive alignment in both research settings and in classroom contexts. Taken together, the findings of prior research and the results of this study suggest that structural alignment is an integral part of task-based communication and that it can provide useful learning opportunities for L2 speakers to enhance their use of L2 structures through authentic interaction. 
Cited as: Dao, P., Trofimovich, P., \& Kennedy, S. (2018). Structural alignment in L2 task-based interaction. ITL-International Journal of Applied Linguistics, 169(2), 293-320.

\section{References}

Bock, J. K. (1986). Syntactic persistence in language production. Cognitive Psychology, 18, $355-387$.

Bock, J. K., \& Griffin, Z. M. (2000). The persistence of structural priming: Transient activation or implicit learning? Journal of Experimental Psychology: General, 129, $177-192$.

Branigan, H. P., Pickering, M. J., \& McLean, J. F. (2005). Priming prepositional-phrase attachment during comprehension. Journal of Experimental Psychology: Learning, Memory, and Cognition, 31(3), $468-481$.

Branigan, H., Pickering, M., \& Cleland, A. (2000). Syntactic coordination in dialogue. Cognition, 75, 13-25.

Branigan, H., Pickering, M., Person, J., \& McLean, J. (2010). Linguistic alignment between people and computers. Journal of Pragmatics, 42, 2355-2368.

Chang, F., Dell, G. S., Bock, J. K., \& Griffin, Z. M. (2000). Structural priming as implicit learning: A comparison of models of sentence production. Journal of Psycholinguistic Research, 29, 217-229.

Clark, H. (1992). Arenas of language use. Chicago, IL: University of Chicago Press.

Colina, A. A. \& Garcia-Mayo, M. P. (2007). Attention to form across collaborative tasks by low-proficiency learners in an EFL setting. In M. P. Garcia-Mayo (Ed.), Investigating tasks in formal language learning, (pp. 91-116). Clevedon: Multilingual Matters Ltd.

Collentine, J., \& Collentine, K. (2013). A corpus approach to studying structural convergence in task-based Spanish L2 interactions. In K. McDonough \& A. Mackey (eds.), Second language interaction in diverse educational contexts (pp. 167-188). Amsterdam: Benjamins. 
Cited as: Dao, P., Trofimovich, P., \& Kennedy, S. (2018). Structural alignment in L2 task-based interaction. ITL-International Journal of Applied Linguistics, 169(2), 293-320.

Costa, A., Pickering, M. J. \& Sorace, A. (2008). Alignment in second language dialogue. Language and Cognitive Process, 23(4), 528-556.

Foster, P. \& Skehan, P. (1996). The influence of planning and task type on second language performance. Studies in Second Language Acquisition, 18 (3), 299 - 323.

Garrod, S., \& Pickering, M., J. (2009). Joint action, interactive alignment, and dialog. Topics in Cognitive Science, 1, 292 -304.

Gass, S. (1997). Input, interaction, and second language learner. Mahwah, NJ: Lawrence.

Gass, S., \& Varonis, M. (1985). Variation in native speaker speech modification to nonnative speakers. Studies in Second Language Acquisition, 7, 37 -57.

Goldberg, A. E. (1995). Constructions: A construction grammar approach to argument structure. Chicago: Chicago University Press.

Goldberg, A. E. (2006). Construction at work: The nature of generalization in language. Oxford: Oxford University Press.

Gries, S. (2005). Syntactic priming: A corpus-based approach. Journal of psycholinguistic research, 34, $365-399$.

Jiang, L., \& Huang, K. (2015). The efficacy of structural priming on the acquisition of double object construction by Chinese EFL learners. Higher Education Studies, 5, 38-49.

Kim, M., Horton, W., Bradlow, A. (2010). Phonetic convergence in spontaneous conversation as a function of interlocutor language distance. Laboratory Phonology, 2, $125-156$.

Kim, Y. (2013). Promoting attention to form through task repetition in a Korean EFL context. In: K. McDonough, \& A. Mackey (Eds.). Second language interaction in diverse educational context (pp. 3-24). Amsterdam: John Benjamins.

Kim, Y., \& McDonough, K. (2008). The effect of interlocutor proficiency on the 
Cited as: Dao, P., Trofimovich, P., \& Kennedy, S. (2018). Structural alignment in L2 task-based interaction. ITL-International Journal of Applied Linguistics, 169(2), 293-320.

collaborative dialogue between Korean as a second language learners. Language Teaching Research, 12, (2), 211-234.

Lambert, C., Philp, J. \& Nakamura, S. (2017). Learner-generated content and engagement in second language task performance. Language Teaching Research, 21, 665-680.

Levkina, M., \& Gilabert, R. (2012). The effects of cognitive task complexity on L2 oral production. In A. Housen, F. Kuiken, I. Vedder (Eds.), Dimensions of performance and proficiency: Complexity, accuracy and fluency in SLA, (pp. 171 -198). Amsterdam: John Benjamins.

Long, M. H. (1996). The role of the linguistic environment in second language acquisition. In W. C. Ritchie \& T. K. Bahatia (Ed.), Handbook of research on language acquisition (pp. 413 - 468). NY: Academic Press.

Mackey, A. (2007). Interaction as practice. In R. DeKeyser (Ed.), Practice in second language learning. Perspective from linguistics and psychology (pp. 85-110). Cambridge: Cambridge University Press.

Mackey, A. (2012). Input, interaction and corrective feedback in L2 learning. Oxford: Oxford University Press.

Mackey, A., \& Gass, S. (2006). Introduction. Studies in Second Language Acquisition, 28, 169-178.

McDonough (in review). Using structural priming tasks in an EAP context.

McDonough, K. (2006). Interaction and syntactic priming: English L2 speakers' production of dative constructions. Studies in Second Language Acquisition, 28, 179-207.

McDonough, K., \& Chaikitmongkol, W. (2010). Collaborative syntactic priming activities and EFL learners' production of wh-questions. Canadian Modern Language Review, 66, 817-841. 
Cited as: Dao, P., Trofimovich, P., \& Kennedy, S. (2018). Structural alignment in L2 task-based interaction. ITL-International Journal of Applied Linguistics, 169(2), 293-320.

McDonough, K., \& Kim, Y. (2009). Syntactic priming, type frequency, and EFL learners' production of wh-questions. The Modern Language Journal, 93, 386-398.

McDonough, K., \& Mackey, A. (2008). Syntactic priming and ESL question development. Studies in Second Language Acquisition, 30, 31-47.

Michel, M., \& Smith, B. (2017). Measuring lexical alignment during L2 chat interaction: An eye-tracking study. In S. M. Gass, P. Spinner, \& J. Behney (eds.), Salience in second language acquisition, (pp. 246 -266). New York: Routledge.

Nuevo, A., Adams, R. \& Ross-Feldman, R. (2011). Task complexity, modified output, and L2 development in learner-learner interaction. In R. Robinsons (Ed.), Second language task complexity: Researching the cognition hypothesis of language learning and performance, (pp. 175 -202). Amsterdam: John Benjamins.

Ohta, A.S. (2001). Second Language Acquisition Processes in the Classroom: Learning Japanese. Mahwah, NJ: Erlbaum.

Oliver, R. (2002). The patterns of negotiation for meaning in child interactions. Modern Language Journal, 86, 97-111.

Pica, T. (1994). Research on negotiation: what does it reveal about second language learning conditions, processes, and outcomes? Language Learning, 44, 493-527.

Piccardo, E. (2013). Plurilingualism and curriculum design: Toward a synergic vision. TESOL Quarterly, 47, 600-614.

Pickering, M. J., \& Branigan, H. P. (1998). The representation of verbs: Evidence from syntactic priming in language production. Journal of Memory and Language, 39(4), 633 651.

Pickering, M. \& Ferreira (2008). Structural priming: A critical review. Psychological Bulletin, 134 (3), 427-459. 
Cited as: Dao, P., Trofimovich, P., \& Kennedy, S. (2018). Structural alignment in L2 task-based interaction. ITL-International Journal of Applied Linguistics, 169(2), 293-320.

Pickering, M. J., \& Garrod, S. (2004). Toward a mechanistic psychology of dialogue. Behavioral and Brain Sciences, 27, 169-225.

Pickering, M. J., \& Garrod, S. (2013). An integrated theory of language production and comprehension. Behavioral and Brain Sciences, 36, 329-392.

Reitter, D., \& Moore, J. D. (2014). Alignment and task success in spoken dialogue. Journal of Memory and Language, 76, $29-46$.

Phung, L. (2017). Task preference, affective response, and engagement in L2 use in a US university context. Language Teaching Research, 21, 75 -766.

Savage, C., Lieven, E., Theakston, A., \& Tomasello, M. (2003). Testing the abstractness of children's linguistic representations: Lexical and structural priming of syntactic constructions in young children. Developmental Science, 6, 557 -567.

Savage, C., Lieven, E., Theakston, A., \& Tomasello, M. (2006). Structural priming as implicit learning in language acquisition: The persistence of lexical and structural priming in 4-year-olds. Language Learning and Development, 2, 27 -49.

Shin J., \& Christianson, K. (2012). Structural priming and second language learning. Language Learning, 63 (3), 931-964.

Smith, M., \& Wheeldon, L. (2001). Syntactic pirming in spoken sentence production: An online study. Cognition, 78(2), $123-164$.

Storch, N. (2001). How collaborative is pair work? ESL tertiary students composing in pairs. Language Teaching Research , 5, 29-53.

Swain, M. (1995). Three functions of output in second language learning. In G. Cook \& B. Seidlhofer (Ed.), Principle and practice in applied linguistics: Studies in honour of $H$. G. Widdowson (pp. 125- 144). Oxford: Oxford University Press.

Swain, M. (2005). The output hypothesis: Theory and research. In E. Hinkel (Ed.), Handbook 
Cited as: Dao, P., Trofimovich, P., \& Kennedy, S. (2018). Structural alignment in L2 task-based interaction. ITL-International Journal of Applied Linguistics, 169(2), 293-320.

of research in second language teaching and learning (pp. 471-484). Mahwah, NJ: Lawrence Erlbaum.

Van Engen, K., Baese-Berk, M., Baker, R., Kim, M. \& Bradlow, A. (2010). The Wildcat corpus of native and foreign-accented English: Communicative efficiency across conversational dyads with varying language alignment profiles. Language \& Speech, $53,510-540$.

Vygotsky, L. S. (1978). Mind in society. Cambridge, Mass.: MIT Press.

Watanabe, Y., \& Swain, M. (2007). Effects of proficiency differences and patterns of pair interaction on second language learning: collaborative dialogue between adult ESL learners. Language Teaching Research, 11, $121-142$.

Yule, G. \& Macdonald, D. (1990). Resolving referential conflict in L2 interaction: The effect of proficiency and interactive role. Language Learning 40, 539-556. 
Cited as: Dao, P., Trofimovich, P., \& Kennedy, S. (2018). Structural alignment in L2 task-based interaction. ITL-International Journal of Applied Linguistics, 169(2), 293-320.

Appendix A. Materials Used in the Picture and Map Tasks

Picture task

Set 1
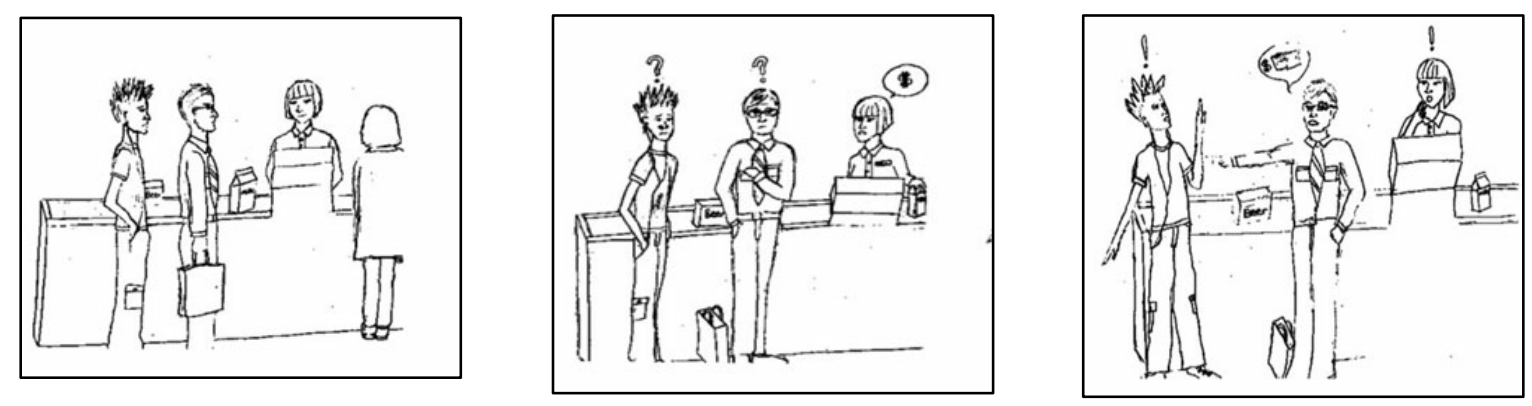

Set 2

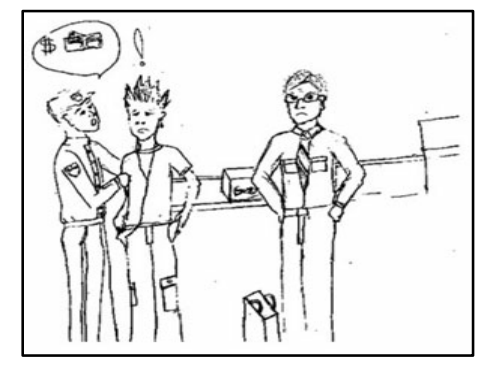

Map Task

Complete map

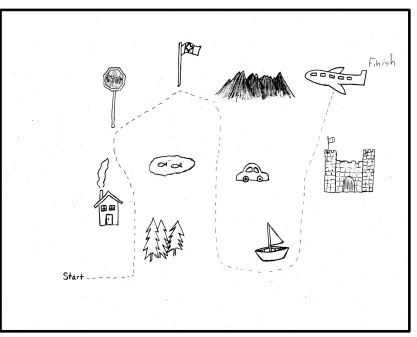

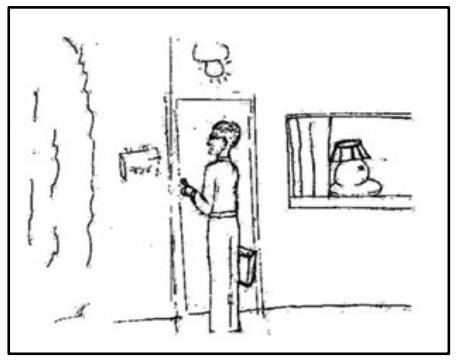

Set 1

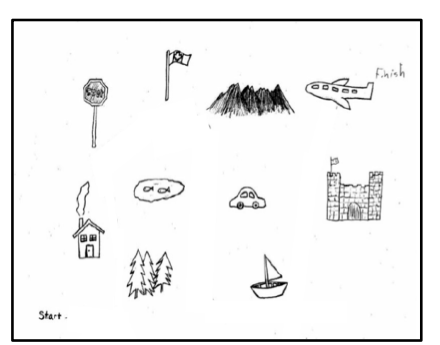

Set 2
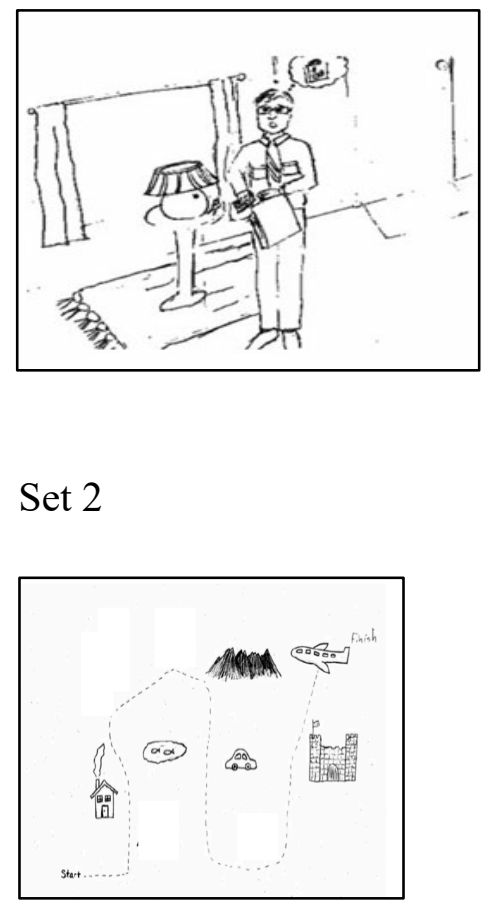
Cited as: Dao, P., Trofimovich, P., \& Kennedy, S. (2018). Structural alignment in L2 task-based interaction. ITL-International Journal of Applied Linguistics, 169(2), 293-320.

Appendix B. Task Features and Task Implementation Condition

\begin{tabular}{|c|c|c|c|c|c|c|}
\hline Task & Goals/outcome & Interactive role & Target structures & Input & Procedure & Interaction promoted \\
\hline Map & $\begin{array}{l}\text { Understand and } \\
\text { exchange unknown } \\
\text { information, } \\
\text { converge on a } \\
\text { solution (closed } \\
\text { outcome): a } \\
\text { complete map of } 10 \\
\text { landmarks and a } \\
\text { route }\end{array}$ & $\begin{array}{l}\text { Obtain missing } \\
\text { information, act } \\
\text { as provider and } \\
\text { receiver of } \\
\text { information }\end{array}$ & $\begin{array}{l}\text { Prepositions of } \\
\text { place, lexical } \\
\text { items (e.g., } \\
\text { location, } \\
\text { direction of route, } \\
\text { landmarks) }\end{array}$ & $\begin{array}{l}\text { Pictorial input, } \\
\text { relatively } \\
\text { imbalanced: One } \\
\text { speaker has a map } \\
\text { with } 10 \text { landmarks } \\
\text { but no route whereas } \\
\text { the other has a route } \\
\text { and only six } \\
\text { landmarks }\end{array}$ & $\begin{array}{l}\text { Pair work, no } \\
\text { planning time }\end{array}$ & $\begin{array}{l}\text { Taking turns as a giver and a } \\
\text { receiver of information } \\
\text { targeting individual lexical } \\
\text { items (i.e., landmarks, location, } \\
\text { direction) in a question-answer } \\
\text { sequence }\end{array}$ \\
\hline
\end{tabular}

